\title{
PENERAPAN METODE MOVING AVERAGE DAN DIGITAL TERRAIN MODEL UNTUK VISUALISASI BATIMETRI 3 DIMENSI DATA ECHOSOUNDER
}

\section{APPLICATION OF MOVING AVERAGE METHOD AND THE DIGITAL TERRAIN FOR 3 DIMENSION DATA MULTIBEAM ECHOSOUNDER VISUALIZATION}

\author{
Fahrulian $^{1}$, Henry M Manik ${ }^{2}$, Indra Jaya ${ }^{2}$ \\ ${ }^{1}$ Program Studi Teknologi Kelautan, Sekolah Pascasarjana \\ ${ }^{2}$ Departemen Ilmu dan Teknologi Kelautan, \\ Fakultas Perikanan dan Ilmu Kelautan, Institut Pertanian Bogor \\ Korespondensi: Fahrulian@gmail.com,Henrymanik@yahoo.com
}

\begin{abstract}
Data and information about seabed topography is very important, among others for safety navigation and strategic planning other. This paper describes a combination of multibeam echosoder data and Digital Terrain Model (DTM) methode to seen the appearance of the seabed. Moving average method chosen because it is very suitable to be applied in large number of data multibeam. The end result of the combination of the two methods were the three-dimensional visualization. This method used multibeam echosounder data that has been corrected and begins of formation of gridding that represent values that exist along the lines survey. The value of each gridding will be form distribution value of all sounding data. Shadding relief and wireframe visualization sheet is the key to building a DTM. The process of merging the existing layer is used to saw smooth appearance through the implementation of lighting settings that will produce a better image. A simple analysis slope can be seen by the results of this DTM.
\end{abstract}

Keyword: bathymetri, Digital Terrain Model, moving average, three dimension

\begin{abstract}
ABSTRAK
Data dan informasi mengenai bentuk topografi dasar laut sangat penting, antara lain untuk kepentingan kemanan pelayaran dan juga penting untuk kajian strategis lainnya. Makalah ini menjelaskan tentang kombinasi data multibeam echosounder dan metode Digital Terrain Model (DTM) untuk melihat kenampakan dasar laut. Metode moving average dipilih karena sangat cocok untuk diterapkan pada data multibeam yang berjumlah banyak. Hasil akhir dari kombinasi dua metode tersebut adalah visualisasi 3 dimensi. Metode ini menggunakan data multibeam echosounder yang telah dikoreksi dan diawali proses pembentukan gridding yang mewakili nilai-nilai yang ada disepanjang lajur survei. Nilai dari masing-masing gridding akan membentuk sebaran nilai seluruh data sounding. shadding relief dan visualisasi wireframe sheet menjadi kunci untuk membangun sebuah DTM. Proses penggabungan layer yang ada digunakan untuk melihat kenampakan secara halus melalui penerapan pengaturan pencahayaan sehingga akan menghasilkan citra yang lebih halus. Analisis sederhana mengenai kemiringan (slope) dapat terlihat dengan adanya hasil DTM ini.
\end{abstract}

Kata kunci: batimetri, Digital Terrain Model, moving average, tiga dimensi 


\section{PENDAHULUAN}

\section{Latar belakang}

Sistem pengukuran modern yang saat ini dilakukan untuk mengetahui kontur dasar laut secara luas dan menyeluruh secara bersamaan hanya dapat digunakan melalui metode remote sensing khususnya sistem akustik bawah air. Sistem ini mampu untuk melakukan observasi terhadap objek yang berada di bawah permukaan perairan. Penggunaan multibeam echosounder akan sangat membantu untuk memperoleh data kedalaman secara luas dengan prinsip sapuan (Dufek 2012). Pengukuran dengan sistem ini akan menghasilkan jumlah data yang banyak dari sisi kuantitatif dan memiliki akurasi yang sangat baik (Anderson et al. 2008).

Pembuatan peta kontur bawah laut dibangun atas dasar pembentukan grid. Proses gridding dapat ditentukan melalui beberapa metode seperti kriging, minimum curvature, nearest neighbour, natural neighbour, Modified Shepard's Method, Radial Basis Function, The Polynomial Regression, inverse distance to a power, The Triangulation with Linear Interpolation, moving average, dan metode artificial intelligence (Hamilton 1980; Stateczny 2000; Lubczonek and Stateczny 2003; Humborstad 2004; Gosciewski 2014).

Pada penelitian ini, jenis gridding data yang digunakan adalah moving average. Metode ini sangat cocok digunakan pada set data yang berjumlah banyak (minimal $>1000$ data). Pembuatan grid yang berasal dari data hasil sounding ini juga mutlak diperlukan untuk membangun sebuah Digital Terain Model (DTM) yang baik. Metode moving average bukanlah metode terbaik, namun para peneliti masih menggunakannya dikarenakan memiliki formulasi yang sederhana namun tetap menghasilkan gridding data yang cukup memadai (Maleika 2014).

\section{METODE PENELITIAN}

\section{Data kedalaman}

Data kedalaman yang digunakan dalam penelitian ini terdiri dari XYZ yang merupakan data hasil sounding dengan menggunakan multibeam echososunder jenis SIMRAD EM 120 yang telah dikoreksi. Datum yang digunakan untuk wilayah ini adalah WGS84 yang berlaku secara global dan menggunakan Universal Transverse Mercator
(UTM). Lokasi pemeruman berada pada zona $47 \mathrm{~N}$ berdasarkan aturan internasional.

\section{Gridding moving average}

Metode ini merupakan metode yang sangat terkenal dalam pemrosesan dan analisis sinyal secara teknis maupun dalam penggunaannya sebagai filter data (Jobman 1995; Hellerstein et al. 2003; Yongzhen et al. 2007). Metode ini didasarkan pada mencari nilai rata-rata dari sekumpulan data yang dimiliki dengan menggunakan $\mathrm{n}$ data sebagai faktor rata-rata. Semakin tinggi nilai $\mathrm{n}$ yang digunakan, maka suatu kumpulan data akan menghasilkan grafik yang lebih halus. Metode ini sering disertakan pada perangkat lunak yang berfungsi untuk menyajikan data geospastial seperti aplikasi Sistem Informasi Geografis (SIG).

Perhitungan nilai dari metode ini didadasarkan pada fungsi jarak secara spesifik. Jika nilai yang di rata-ratakan memiliki kedekatan terhadap nilai output, maka nilai output diperoleh oleh nilai itu sendiri. Algortima pembentuk metode ini dibentuk melalui dua langkah, yaitu :

1. Untuk nilai output, jarak terhadap titik disekelilignya dihitung untuk menentukan nilai bobot. Terdapat dua metrik utama dalam kasus ini :

Jarak terbalik :

$$
\text { Bobot }=\frac{1}{d^{n}}-1
$$

Penurunan linear :

$$
\text { Bobot }=1-\mathrm{d}^{\mathrm{n}}
$$

2. Dimana d merupakan jarak relatif satu titik terhadap titik output. Pembobotan secara sederhana dibentuk melalui persamaan:

$$
\text { Nilai ouput }=\frac{\sum(\text { Wi.val })_{i}}{\sum W_{i}}
$$

dengan :

$\mathrm{Wi} \quad=$ Nilai bobot untuk titik i

Vali $=$ Nilai titik $\mathrm{i}$

\section{Interpolasi data multibeam}

Secara umum proses ini akan membentuk suatu titik nilai kedalaman baru berdasarkan titik yang sudah ada. Fungsi proses ini untuk mengsi gap data atau data yang kosong selama proses sounding. Secara umum proses ini mengggunakan algoritma yang terbagi menjadi 2 , yaitu ratarata spasial dan rata-rata temporal sehingga 
proses interpolasi merupakan gabungan dari kedua rata-rata tersebut dan ditulis:

$$
\bar{x}=\frac{h X_{i}^{t}-m X_{i}^{s}}{h+m}
$$

dengan:

$X_{i s}^{t}=$ Rata-rata temporal

$X_{i}^{s}=$ Rata-rata spasial

$\mathrm{h}=$ Akumulasi bobot rata-rata temporal

$\mathrm{m}=$ Akumulasi bobot rata-rata spasial

\section{Digital Terain Model (DTM)}

Konsep DTM pada mulanya populer digunakan untuk kepentingan daratan. Jenis ini biasanya digunakan untuk melihat beberapa aspek yang terjadi di darat seperti kemiringan dan elevasi daratan. Namun seiring perkembangan waktu, DTM juga mampu untuk diapliasikan kedalam dunia kelautan. Secara umum DTM didefiniskan sebagai sekumpulan set data yang mewakili distribusi spasial dari berbagai jenis informasi tentang sebuah medan lokasi (Miller dan Lafflame 1985).

DTM menerapkan prinsip digital dan numerik yang memperkecil skala dari ukuran sebenarnya dan bertujuan agar pengguna mampu untuk memahaminya (Meyer 1985). Beberapa input dibutuhkan dalam proses konstruksi ini. Semakin banyak informasi yang dimasukkan maka akan menghasilkan data yang sangat lengkap di akhir layernya. Secara matematis konsep ini ditulis dalam :

$$
\begin{aligned}
& \mathrm{KP}=\mathrm{f}(\mathrm{uP}, \mathrm{vP}) \\
& \mathrm{K}=1,2,3, \ldots, \mathrm{m} \\
& \mathrm{P}=1,2,3, \ldots, \mathrm{n}
\end{aligned}
$$

Sebuah penelitian yang dilakukan sebelumnya oleh Li pada tahun 1990 menjelaskan bahwa terdapat sedikitnya ada 6 tahapan utama dengan masing-masing tahapan terdiri dari beberapa kegiatan. Proses tersebut diawali dari pembuatan project hingga dari kegiatan tersebut menghasilkan produk akhir berupa peta yang siap digunakan oleh pengguna. Gambar 1 menerangkan skematik atau alur kegiatan dari masing-masing tahapan.

\section{Rendering geometri}

Proses ini berguna untuk membangun sebuah geometri yang dihasilkan dari model gridding yang dibuat sebelumnya. Rendering bertujuan untuk meningkatkan visualisasi permukaan dari data kedalaman. Syarat pembentukan yang harus dipenuhi dalam proses ini minimal terdiri dari dua buah file raster data. Satu file teridiri dari informasi mengenai tekstur warna dan raster yang lain terdiri dari informasi elevasi kedalaman. Kedua data tersebut harus dalam format data yang sama. Secara matematis rendering dapat dibuat dalam :

$$
\begin{aligned}
& I\left(x, x^{\prime}\right)=g\left(x, x^{\prime}\right)\left[\in\left(x, x^{\prime}\right)+\int s p\left(x, x^{\prime}, x\right)\right] \\
& \text { dengan : } \\
& \mathrm{I}\left(\mathrm{x}, \mathrm{x}^{\prime}\right)=\text { Intensitas cahaya yang } \\
& \text { melewati titik } \mathrm{x} \text { " terhadap } \\
& \text { titik } \mathrm{x} \text {. } \\
& \mathrm{g}\left(\mathrm{x}, \mathrm{x}^{\prime}\right)=\text { Ukuran Geometri } \\
& \epsilon\left(x, x^{\prime}\right)=\text { Intensitas cahaya yang } \\
& \text { diemisikan dari titik x' ke } \\
& \text { titik } \mathrm{x} \\
& \mathrm{p}\left(\mathrm{x}, \mathrm{x}^{\prime}, \mathrm{x}^{\prime \prime}\right)=\quad \text { Intensitas cahaya yang } \\
& \text { dihamburkan dari } x \text { " terhadap } \\
& \mathrm{x} \text { melalui patch pada } \\
& \text { permukaan } x^{\prime}
\end{aligned}
$$

\section{HASIL DAN PEMBAHASAN}

\section{Gridding data kedalaman (XYZ)}

Proses gridding yang dilakukan dengan menggunakan metode ini dilakukan secara elliptical untuk mencari neighborhood value dalam pembentukan node atau simpulsimpulnya. Simpul ini merupakan titik temu antara garis vertikal dan horizontal yang terbentuk secara imaginer yang akan membentuk titik-titik pengamatan data kedalaman menjadi lebih teratur. Simpul tersebut hanyalah garis bantu untuk membentu grid-grid sederhana dari data titik yang ada. Proses analisis signal dari data dapat dilakukan dengan menggunakan perangkat lunak lainnya seperti matlab yang berbasis bahasa pemrograman dengan memasukkan syntax sederhana seperti :

load Data.mat \% memuat data yang ada $\mathrm{X}=$ example $1 ; \%$ input data 1 $\mathrm{Y}=$ example $2 ; \%$ input data 2 $\mathrm{Z}=$ example3; \% input data 3 window_size $=12 \%$ size data simple = tsmovavg(z,'s',window_size, 1$)$; 
$\%$ fungsi moving average plot $(\mathrm{Y}$, simple,... datetick legend ('example 1', 'example 2') \% memberikan keterangan legenda title (Judul grafik') \% memberi keterangan judul.

Data kedalaman yang berasal dari multibeam echosounder relatif sangat rapat dan sudah teratur. Oleh karena itu nilai gridding yang dihasilkan melalui data ini sangat banyak. Selain itu juga radius elliptical yang dihasilkan memiliki nilai yang kecil. Search ellipse 1 dan 2 dari data ini bernilai 0.05. Berdasarkan nilai tersebut, dapat diperoleh informasi bahwa jarak antara titik satu dan titik yang lainnya sangat dekat. Sehingga simpul yang dihasilkan juga memiliki jarak yang sangat dekat. Selain itu, nilai search ellipse angle yang dihasilkan memiliki nilai 0 . Artinya bahwa titik satu dan titik lain yang akan mengalami proses gridding masih berada dalam garis horizontal yang sama. Jumlah simpul atau node yang dihasilkan cukup banyak, nilai ini diperoleh melaui informasi grid size yang dihasilkan. Ukuran geometri dari data ini yaitu 100 x 45 . Nilai 100 menyatkan banyaknya baris dan 45 menyatakan bayaknya kolom. Sehingga total terdapat 4500 simpul yang dihasilkan. Tabel 1 menyajikan informasi hasil dari gridding menggunakan moving average.

Proses gridding yang telah dilakukan memiliki nilai-nilai pada setiap gridnya. Nilai yang ada pada masing-masing grid merupakan representasikan nilai kedalaman pada titik koordinat. Namun yang penting diingat dalam konsep gridding adalah, nilai kedalaman tersebut hasil interpolasi yang nilainya tidak berbeda secara signifikan dengan data sebenenarnya. Nilai tersebut akan dijadikan pedoman untuk menghasilkan nilai kontur kedalaman atau isodepth dari suatu perairan. Dengan adanya grid ini, maka dapat mengubah, menambahkan atau mengurangi nilai kedalaman suatu perairan. Gambar 1 merupakan hasil gridding data kedalaman.

Data yang sudah mengalami grid akan memiliki tanda plus (+) pada basemap. Selain itu juga data gridding akan memeberikan pola secara kasar yang berbentuk garis kontur. Kontur ini merupakan sebuah segmentasi dari perbedaan elevasi dari topograi dasar laut. Hampir sebagian besar perangkat lunak Sistem Informasi Geografis (GIS) mengharuskan untuk melakukan grid data terlebih dahulu untuk membangun Digital Terain Model (DTM). Oleh karena itu gridding data mutlak diperlukan untuk membangn visualisasi data 2 dimensi atau 3 dimensi. Gambar 2 merupakan garis kontur yang dibangun dari hasil gridding.

Secara sederhana gridding mampu untuk membedakan dan mengelompokkan data-data yang memiliki kedalaman yang sama. Berdasarkan data, maka garis kontur atau isodepth yang berhasil dibentuk adalah data kedalaman yang berada pada rentang 560 meter hingga 660 meter. Tampilan tersebut masih belum mampu untuk menggambarkan secara utuh kondisi yang sebenarnya. Hasil kontur dapat dilihat pada Gambar 3.

Proses berikutnya untuk membangun batimetri 3 dimensi yang umum dilakukan adalah menghasilkan topografi dengan shade relief. Citra yang dihasilkan dari proses ini berupa raster data set. Hal ini ditandai dengan citra yang dihasilkan berbasis pixel. Pada dasarnya informasi mengenai dasar perairan lebih mudah diamati dan real dibandingkan dengan menggunakan peta kontur atau hasil gridding (Cammarano 2004). Pada umumnya citra yang telah mengalami proses shading telah mengalami pengaturan pencahayaan dalam output filenya (Jenny 2001).

Shade relief data kedalaman telah menghasilkan sebuah model topografi dasar laut dalam bentuk 2 dimensi secara sederhana. Perbedaan tinggi rendahnya kedalaman diatur dalam bentuk gambar dengan grayscale colour map. Secara sederhana kemiringan dasar laut dapat dianalisis dengan menggunakan citra ini. Warna hitam pada citra merepresentasikan bahwa keadaan di lokasi tersebut memiliki elevasi yang relatif lebih rendah dibanding dengan warna yang lebih putih. Kombinasi antara data kedalaman dan kemiringan juga dapat dianalisis melalui shade relief (Batson et al. 1975). Hasil shade relief dapat dilihat pada Gambar 4.

Pembuatan grid, konturing dan shading relief yang telah dilakukan sebelumnya merupakan ploting data yang bersifat 2 dimensi saja. Representasi 3 dimensi secara sederhana dibangun melalui proses wireframe. Data yang dibutuhkan untuk membangun tipe file ini sudah menggunakan vektor $Z$ sebagai nilai kedalaman yang di plot secara vertikal. Wireframe data dibentuk melalui hubungan nilai kedalaman $Z$ disepanjang jalur survei pada titik koordinatnya. Masing-masing koordinat tersebut akan mengalami titik potong atau intersection tepat pada simpulnya. Setiap titik simpul trsebut akan memiliki nilai kedalaman. Gambar 5 merupakan hasil pembentukan 3 dimensi 
dengan menggunakan data wireframe. Bentuk topografi dasar laut akan lebih jauh jelas terlihat ketika data-data tersebut di plot. dan kemiringan juga dapat dianalisis melalui shade relief (Batson et al. 1975).

Derajat kehitaman warna yang dihasilkan proporsional terhadap Cosinus sudut antara garis normal dan vektor sumber pencahayaan (Foley et al. 1994). Berdasarkan Gambar 4, terlihat adanya cekungan dasar laut di tengah lokasi pengambilan data. Cekungan tersebut berbentuk seperti palung yang sangat luas dan dalam. Dapat juga terlihat bahwa sisi-sisi gambar relatif berbentuk landai tanpa adanya perbedaan ketinggian yang signifikan. Wireframe pada dasarnya sudah cukup informatif memberikan gambaran kondisi perairan. Namun belum cukup baik jika disajikan dalam proses pembuatan peta jadi.

Proses rendering yang dilakukan dalam penelitian ini memanfaatkan metodologi penggabungan dari beberapa layer yang telah terbentuk. Struktur data tersebut dibangun berdasarkan hierarikal berbentuk piramid. Beberapa layer yang digunakan dalam proses ini antara lain: gridding file, shadding relief map, dan wireframe sheet. Output atau hasil umum yang diperoleh ketika kita melakukan survei hydrografi dengan bantuan echosounder adalah batimetri beserta legendanya. Penggunaan DTM dapat digunakan oleh hydrografer sebagai tools untuk membuat visualisasi dari dasar perairan (Laurini and Thompson 1992). Pembuatan peta topografi dasar laut yang tepat nantinya diharapkan dijadikan sebagai informasi utama untuk pelayaran kapal maupun kepentingan taktis lainnya yang berhubungan dengan kelautan. Gambar 6 merupakan hasil perpaduan beberapa layer yang yang telah dibuat sebelumnya dan menghasilkan output citra digital berupa model batimetri dasar perairan secara 3 dimensi.

Tabel 1. Gridding parameter dari moving average

\begin{tabular}{lc}
\hline \multicolumn{1}{c}{ Parameter } & Nilai \\
\hline Search Ellipse Radius \#1 & 0.05 \\
Search Ellipse Radius \#2 search ellipse angle & 0.05 \\
Grid Size & \\
Filled Nodes & $0^{\circ}$ (degree) \\
Total Nodes & $100 \times 45$ \\
Grid Geometry & 4.500 \\
X Spacing & 4.500 \\
Y Spacing & \\
Blanked Nodes & 0.000923165 \\
Blank Value & 0.000926160 \\
& 0 \\
& $1.70141 \mathrm{E}+038$ \\
\hline
\end{tabular}

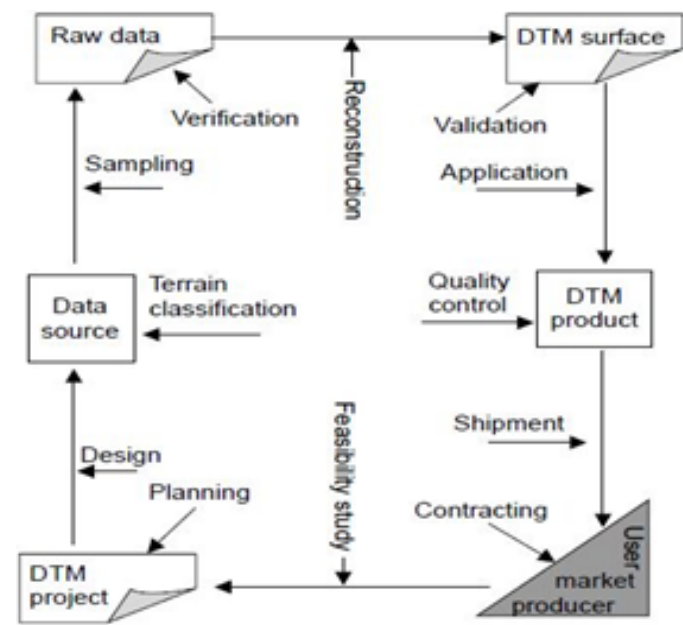

Gambar 1. Diagram proses Digital Terain Model (DTM) (Li 1990) 


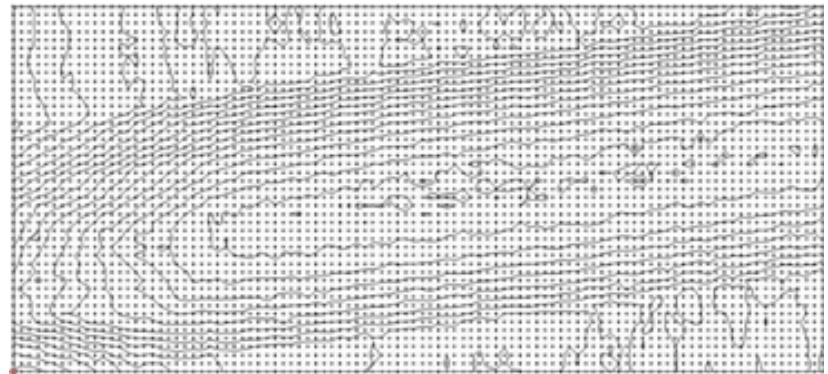

Gambar 2. Pembentukan grid berdasarkan data kedalaman multibeam echosounder

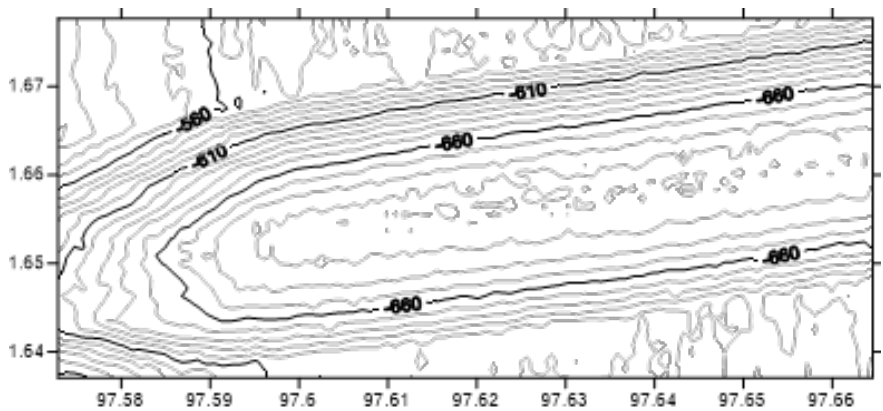

Gambar 3. Konturing secara sederhana yang dihasilkan dari proses gridding

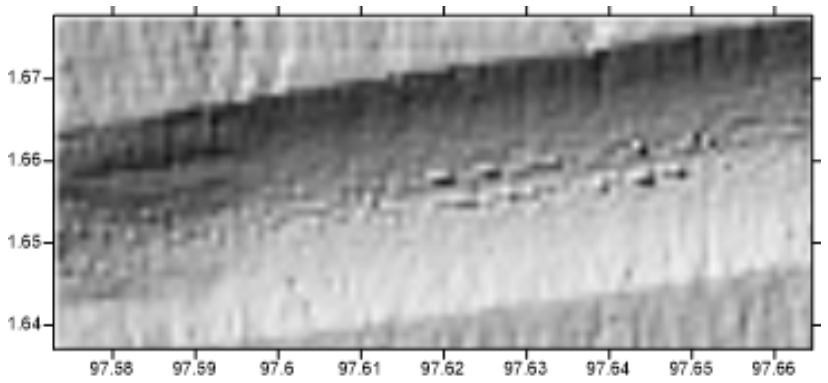

Gambar 4. Shading relief yang dihasilkan berdasarkan data kedalaman

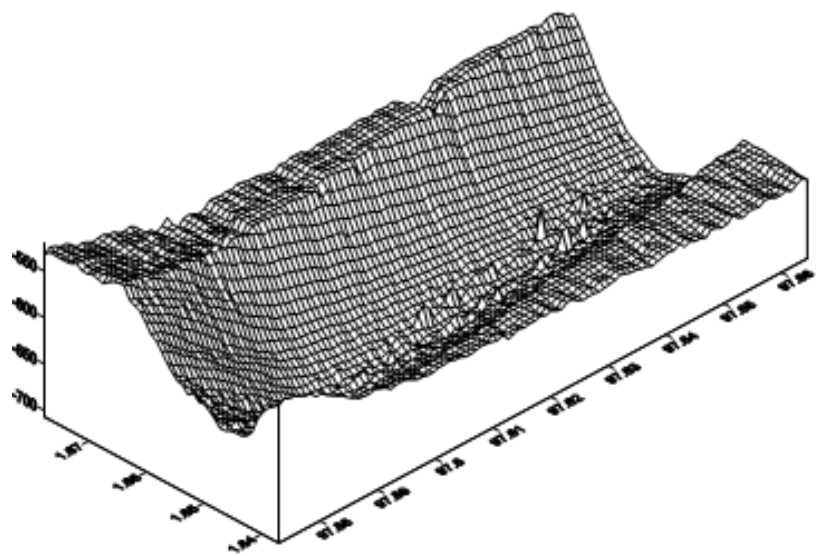

Gambar 5. Wireframe 3 Dimensi data kedalaman 


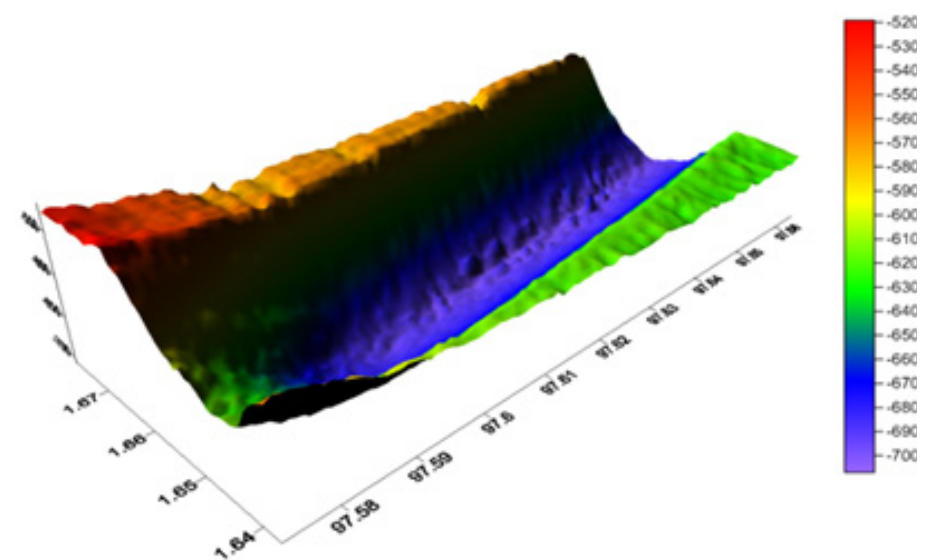

Gambar 6. Produk akhir penggabungan metode moving average dan DTM untuk pemetaan topografi dasar laut secara 3 dimensi

\section{KESIMPULAN DAN SARAN}

Proses gridding menjadi kunci dalam membangun sebuah terrain model. Pembuatan visualisasi data multibeam echososunder dengan menggabungkan metode moving average dan DTM terbukti informatif dalam memberikan gambaran mengenai kondisi batimetri dasar laut. Berdasarkan hasil yang telah diperoleh, beberapa layer dari DTM dapat digunakan untuk menganalisis secara sederhana mengenai kondisi spesifik di sepanjang jalur survei, seperti kemiringan atau slope.

\section{DAFTAR PUSTAKA}

Anderson JT, Van Holliday D, Kloser R, Reid DG, Simard Y. 2008. Acoustic seabed classification: Current practice and future directions. ICES Journal of Marine Science: Journal du Conseil. 65

Batson R, Edwards K, Eliason E. 1975. Computer-generated shaded-relief images. Journal of Research of the US Geological Survey. 3(4): 401-408.

Cammarano M. 2004. Depicting terrain with shaded relief maps. Internet: http:// graphics. stanford. edu/ mcammara/ vis2004/paper. pdf.

Dufek T. 2012. Backscatter analysis of multibeam sonar data in the area of the valdivia fracture zone using geocoder in caris hips \& sips and ivs. 3d Fledermaus Hafen City Universität Hamburg.

Foley JD, Van Dam A, Feiner SK, Hughes JF, Phillips RL. 1994. Introduction to computer graphics. Addison-Wesley Reading.

Gosciewski D. 2014. Reduction of deformations of the digital terrain model by merging interpolation algorithms. Computers \& Geosciences. 64(61-71).

Hamilton EL. 1980. Geoacoustic modeling of the sea floor. The Journal of the Acoustical Society of America. 68(5): 1313-1340.

Hellerstein JM, Hong W, Madden S, Stanek K. 2003. Beyond average: Toward sophisticated sensing with queries. Pages 63-79. Information Processing in Sensor Networks: Springer.

Humborstad O. 2004. Roxann bottom classification system, sidescan sonar and video-sledge: Spatial resolution and their use in assessing trawling impacts. ICES Journal of Marine Science. 61(1): 53-63. 10.1016/j.icesjms.2003.10.001

Jenny B. 2001. An interactive approach to analytical relief shading. Cartographica: The International Journal for Geographic Information and Geovisualization. 38(12): $67-75$.

Jobman DR. 1995. The handbook of technical analysis. Irwin, New York.

Laurini R, Thompson D. 1992. Fundamentals of spatial information systems Academic press.

Li Z. 1990. Sampling strategy and accuracy assessment for digital terrain modelling University of Glasgow.

Lubczonek J, Stateczny A. 2003. Concept of neural model of the sea bottom surface. Pages 861-866. Neural networks and soft computing, Springer.

Maleika W. 2014. Moving average optimization in digital terrain model generation based on test multibeam echosounder data. Geo-Marine Letters. 35(1): 61-68.

Stateczny A. 2000. The neural method of sea bottom shape modelling for the spatial maritime information system. Pages 251-259. International conference on 
maritime engineering and ports.

Yongzhen Z, Lei C, Wang XS, Jie L. 2007. A weighted moving average-based approach for cleaning sensor data. Pages 38-38. Distributed Computing
Systems, 2007. ICDCS '07. 27th International Conference on.

Zaksek K, Ostiri K, Pehani P, Kokaij Z̆, Polert E. 2012. Hill-shading based on anisotropic diffuse illumination. 